\title{
Hobbes y la teoría del Estado moderno. La lectura de Bobbio *
}

\author{
ERMANNO VitALE \\ Università di Sassari
}

\begin{abstract}
RESUMEN. Este trabajo está dedicado al análisis de dos legados fundamentales de Thomas Hobbes al pensamiento político moderno, en la lectura que de ello ha ofrecido Norberto Bobbio. El primero es un legado de carácter metodológico, que consiste en dar prioridad a la demostratio por encima de cualquier forma de interpretatio. El segundo es el individualismo, cuyas diferentes declinaciones son decisivas para fundar, medir y valorar las diversas fórmulas políticas que el Leviatán, en cuanto esencia del Estado moderno, puede albergar. El trabajo se cierra con un tercer nivel de comparación sobre la fortuna de Hobbes y de Bobbio entre sus contemporáneos y en nuestros días.
\end{abstract}

Palabras clave: Hobbes, Norberto Bobbio, teoría del Estado moderno, «claridad confundente», historia de las ideas políticas.
ABSTRACT. This article gives an account of Thomas Hobbes's two main legacies to the modern political thought, in the reading that Noberto Bobbio has given in many of his works. The first one is a methodological legacy, which consists in the priority of the demonstratio over any kind of interpretatio. The second is individualism, whose different dimensions are decisive to justify, to compare, and to judge the wide range of political formulae that the Leviathan, as nature of the modern State, can hold. The article ends with a third level of comparison of the opposite fortune of Hobbes's and Bobbio's works in their times and ours.

Key words: Hobbes, Norberto Bobbio, Theory of Modern State, «Confusing clarity», History of Political Ideas.

\section{Las lecciones de los clásicos}

Cuando abordamos el estudio de autores que vivieron en siglos pasados la primera exigencia es la de su contextualización histórica y la interpretación filológica correcta de sus textos. Los historiadores de las ideas y los historiadores tout court merecen nuestro mayor reconocimiento por el paciente acopio de materiales que realizan, sin el que la reconstrucción y análisis conceptual de los clásicos resultarían estériles. No obstante, en ocasiones, la contextualización y la filología pierden de vista que la tarea de encuadramiento

* Texto presentado en la primera sesión del Seminario permanente que responde al acrónimo CLASICOS (Colectivo de Lectura, Análisis, Sistematización e Investigación sobre Clásicos de Orientación Social), organizado por el Proyecto académico editorial Theoria cum Pra$x i$, www.ifs.csic.es/colTCP del Instituto de Filosofía (CSIC) y el Grupo de Investigación sobre el Derecho y la Justicia (Universidad Carlos III de Madrid). Trad. cast. de Andrea Greppi. 
histórico se queda corta y que a través de ella no se llega a entender nunca la importancia, ni la relevancia que esos textos tienen para nosotros.

Son estos autores «especiales» los que Bobbio definió como clásicos y cuya lección recomendaba escuchar constantemente, leyéndolos y releyéndolos. Un «clásico» es, para Bobbio, un autor que cumple tres características: es el intérprete auténtico y único del tiempo en que vivió; es siempre actual, en el sentido de que cada generación siente la necesidad de leerlo; y ha sido capaz de construir las teorías-modelo de las que nos servimos en el presente para comprender la realidad ${ }^{1}$. En respuesta a quienes le acusaban de hacer una lectura demasiado «actualizante» de los clásicos del pensamiento político, Bobbio tuvo ocasión de escribir:

En el estudio de los autores del pasado nunca me he sentido particularmente atraído por el espejismo de la llamada contextualización histórica que eleva las fuentes a precedentes, las ocasiones a condiciones, que a menudo se detiene en los detalles hasta perder de vista el conjunto. Me he dedicado, por el contrario, con particular interés, a la identificación de los temas fundamentales, a la clarificación de los conceptos, al análisis de los argumentos, a la reconstrucción del sistema ${ }^{2}$.

Esto vale, sobre todo, en el caso de Hobbes. Frente a los numerosísimos intérpretes - entre lo que se encuentra, por ejemplo, Skinner- que lo estudian como uno más de los autores del siglo XVII inglés, o, al contrario, frente a quienes de forma igualmente errónea lo actualizan y lo convierten en padre del totalitarismo y del fascismo, o, incluso, en antecedente de la teoría de juegos, Hobbes es para Bobbio, ante todo, el autor que supo construir la teoría-modelo del Estado moderno.

Para comprender cabalmente, desde el punto de vista científico, lo que puede haber de especial en Hobbes tomaremos como punto de partida las Reflexiones de un octogenario, en las que Bobbio recapitula los temas de la extraordinaria influencia que tuvo Hobbes sobre su pensamiento y, en general, sobre el pensamiento político moderno y contemporáneo. Reproduzco casi por entero esa página:

Lo reconozco, Hobbes ha sido uno de mis autores. Me ocupé de él durante toda mi vida, a intervalos. Pero no me reconozco otro mérito que el de haberme percatado de la importancia capital del pensamiento político de Hobbes cuando todavía se estudiaba poco, al menos en Italia. Aunque es

${ }^{1}$ Cf. Teoría general de la política, edición de M. Bovero, Trotta, Madrid, 2003, p. 128. Cuando, por el contrario, la necesidad permanente de volver a meditar sobre la obra de un autor es individual, se dirá que Cayo es un autor caro a Ticio, o, como suele decirse, un autor suyo. Así pues, los autores que son «referencia» para otro autor no siempre son clásicos, y viceversa. Sobre este punto me permito remitir a mi trabajo Storia della filosofia e filosofia della storia incluido en V. Pazé (ed.), L'opera di N. Bobbio. Itinerari di lettura, Angeli, Milano, 2005, en particular pp. 44-46.

2 N. Bobbio, Introducción a N. Bobbio, M. Bovero, Sociedad y Estado en la filosofía política moderna, FCE, México, 1986, pp. 7-8. 
comprensible: durante el fascismo su nombre era sospechoso. No se habían dado cuenta de que el Leviatán no era el Estado totalitario sino el Estado moderno, que nace de las cenizas de la sociedad medieval, un cuerpo político que puede encarnarse históricamente en las más diversas formas de gobierno, entre las cuales no está necesariamente la autocrática. El Leviatán es sustancialmente el detentador del monopolio de la fuerza legítima: legítima porque se basa en el consenso de los ciudadanos. [...]

Me había impresionado sobre todo la novedad de Hobbes con respecto al método. El discurso de Hobbes no se basaba ya en el principio de autoridad, histórica o revelada, como ocurría aún en gran parte en el célebre libro de Grotius, sino exclusivamente en argumentos racionales.

Que la influencia de Hobbes sobre el curso de mis ideas se haya producido más en cuanto al método que en cuanto al contenido, como ha sostenido Bovero, es una observación certera. Creo, empero, que también respecto a la sustancia hay idea hobbesianas que contribuyeron a formar mi pensamiento político. Señalo tres: el individualismo, el contractualismo y la idea de paz a través de la constitución de un poder común, que es el tema sobre el cual existe una relación continua y fecunda de concordia discors con Bonanate. Añadiría cierto pesimismo sobre la naturaleza humana y sobre la historia ${ }^{3}$.

En las próximas páginas intentaré seguir —críticamente, como Bobbio nos ha invitado a hacer en todo momento - al menos dos de estas indicaciones. Ante todo, el importante legado metodológico, que en mi opinión no es tan obvio y lineal como podría parecer si nos limitáramos a situarla en la amplia y genérica corriente de una común perspectiva de razón analítica aplicada al derecho y a la política; en segundo lugar, y como consecuencia de lo anterior, el individualismo como visión del mundo, cuyas diferentes posibles declinaciones resultan decisivas para fundar, medir y valorar las diversas fórmulas políticas que el Leviatán, en cuanto esencia del Estado moderno, puede albergar - así como para describir y justificar normativamente las relaciones entre los diferentes Leviatanes en el ámbito global, es decir, respecto de la decisión política fundamental sobre la paz y la guerra. Finalmente, quisiera afrontar un tercer nivel de comparación, referido a la «fortuna» de Hobbes y de Bobbio. Soy consciente que el tema puede parecer extravagante y que precisa ser tratado con gran cautela, cuando menos por la obvia razón de la diferente distancia cronológica que nos separa de ambos autores. Intentaré explicarme mejor. Aparentemente, desde el punto de vista de la fortuna los dos se encuentran en las antípodas: la conventio ad excludendum que en los siglos XVII y XVIII pesó sobre el «impío» Hobbes no le ha tocado ciertamente a Bobbio, un autor al que le ha acompañado un éxito notable más allá de los ámbitos académicos, editorialista de «La Stampa» y senador vitalicio ${ }^{4}$. Pero

${ }^{3}$ N. Bobbio, De senectute y otros escritos biográficos, Einaudi, Torino, 1996, pp. 148-150.

${ }^{4} \mathrm{La}$ «condena» de Hobbes, especialmente en el contexto de su época y del siglo siguiente, ha alimentado todo un filón de estudios hobbesianos. Para encontrar un cambio en la valoración es necesario avanzar hasta el siglo pasado. Sobre esta cuestión, y sobre el panorama de 
quizá también el haber sido objeto de una opuesta, a menudo ambigua e incluso hipócrita, conventio ad includendum puede dar, como intentaré mostrar en las conclusiones, razones para un amargo desencanto.

\section{Las grandes dicotomías}

En el fragmento antes citado, Bobbio identifica la influencia metodológica de Hobbes principalmente en la novedad que constituye la sustitución del principio de autoridad por el de razón. Pero no se trata solamente de contraponer la razón a la fe, o de encontrar un punto de equilibrio más favorable a la razón entendida todavía como iluminación divina o como sentido moral: se trata de proceder al examen de las cuestiones prácticas (morales, jurídicas, políticas) a través de una rigurosa demonstratio a partir de definiciones claras y no de una gastada interpretatio que reproduce la tradición - bien de la pandectística, bien de la exégesis bíblica o de la retórica humanística- y la alimenta con la acumulación autorreferencial de detritos conceptuales que no tienen capacidad heurística alguna ${ }^{5}$.

No obstante, en mi opinión, la lección de método de Hobbes tal como es entendida por Bobbio no se identifica exclusivamente con la preferencia por una razón geométrica, con la razón como facultad de cálculo capaz de construir, apartándose por fin los ignes fatui de la retórica y la erudición vacía, esa filosofía civil que tanta falta les hace a los hombres. Es posible que en la inmediata posguerra Bobbio quisiera presentar a Hobbes, un autor poco conocido y mal comprendido en Italia, también en esta perspectiva, como uno de los instrumentos para liberarse de la retórica y del provincialismo que estaban entre los rasgos típicos de la autobiografía de la nación y que habían sido explotados por el fascismo recién derrotado hasta su completo hundimiento moral y civil. Como sabemos, el hecho de dejar atrás la tradición idealista y la vana filosofía gentiliana para abrir el paso a las ciencias sociales y a una filosofía positiva pero crítica era visto por Bobbio, especialmente en esos años, como el presupuesto indispensable para la reconstrucción del país y para el fortalecimiento de una democracia más estable y madura ${ }^{6}$.

Esto no significa que Bobbio viera ingenuamente a Hobbes como un filósofo tout court de la democracia: lo consideraba más bien como el filósofo que había producido los argumentos más sólidos para la fundación teórica del Estado moderno, cuya legitimidad se funda sobre el consenso, y del que la democracia, entendida como forma de gobierno, es la declinación más conse-

la literatura en el siglo xx, E. Vitale, Dal disordine al consenso. Filosofia e politica in Hobbes, Angeli, Milano, 1994, pp. 199-244.

5 N. Bobbio, Il giusnaturalismo in L. Firpo (ed.), Storia delle idee politiche, economiche e sociali, vol. IV, t. I, Utet, Torino, 1972, pp. 491-558.

${ }^{6}$ Cfr. N. Bobbio, Italia civile, Passigli editori, Firenze, 1986, pp. 15-52. 
cuente, por más que el propio Hobbes la hubiera rechazado explícitamente. Es por esta razón por la que el filósofo inglés se presenta en todo momento - y Bobbio era bien consciente de ello - como un Jano bifronte: por un lado, quiere construir la filosofía civil sobre la base de la argumentación racional, y no sobre dogmas de ninguna clase, pero por otro considera dogmáticamente que la filosofía civil no puede ser más que una, la suya, como una sola era también la geometría euclidea; por un lado, rechaza el principio de autoridad, pero por otro atribuye al soberano el (más estricto control sobre el) poder ideológico, entendiendo la esfera práctica como una dimensión sometida a la autoridad soberana y no como el ámbito de la libre búsqueda de la verdad. Como es sabido, el juicio privado sobre el bien y el mal está en opinión de Hobbes en el origen de las doctrinas sectarias que conducen, si son llevados a sus extremas consecuencias, a la guerra civil y a la disgregación del Estado ${ }^{7}$. Podríamos decir que el autor del Leviatán construye una parte del andamiaje conceptual de la democracia de los modernos, pero al mismo tiempo le resta el oxígeno de la pluralidad de las opiniones y los intereses, como consecuencia quizá del temor a la fragmentación y a la confusión de los poderes propios del universo político medieval.

Así pues, si la aportación metodológica de Hobbes hubiese consistido genéricamente en la definición de la razón como facultad de cálculo y en la consiguiente fundación sobre esa base de la política, habría resultado una aportación no sólo limitada, sino también ambigua. Bobbio se sustrae a esa indeterminación y disuelve la ambigüedad llevando a cabo una recuperación crítica del andamiaje conceptual levantado por Hobbes sin incluir el factor del miedo obsesivo a que el conflicto político, económico, social e ideológico desemboque necesariamente en la guerra civil, un miedo que determina la preferencia por el soberano monocrático. Bobbio encuentra en Hobbes no sólo, pero principalmente, al fundador del contractualismo moderno, ese modelo político que, en contraposición al modelo aristotélico, denomina precisamente hobbesiano. Y el modelo iusnaturalista moderno o hobbesiano, según se prefiera - aquél en el que se pasa del estado de naturaleza a la sociedad civil a través del contrato-, se funda a su vez sobre una visión del mundo individualista. En todas sus diferentes versiones o variaciones, en este modelo los elementos originarios y elementales del universo político sólo pueden ser los individuos tomados aisladamente y nunca las familias, los grupos o las comunidades ${ }^{8}$.

Sin embargo, la objeción es inmediata: con esto hemos pasado ya de las cuestiones metodológicas a las cuestiones sustantivas. El propio Bobbio declara que en su opción por el individualismo y en su afinidad teórica con el

7 Hobbes, De cive, XII, 1; Leviatán, XXIX.

${ }^{8}$ Cfr. N. Bobbio, El modelo iusnaturalista, en N. Bobbio, M. Bovero, Sociedad y Estrado en la filosofía politica moderna, FCE, México, 1986. 
contractualismo es donde se encuentra su deuda «sustancial» y no metodológica con Hobbes. No obstante, si hay un adjetivo que se ha vuelto recurrente al hablar de individualismo, hasta el punto de convertirse en objeto de consenso por superposición entre las posibles declinaciones y concepciones más ambiciosas, es precisamente el adjetivo «metodológico». Como veremos en el próximo apartado, Bobbio consideraba, con razón, inútil e inoportuna esa acepción «mínima», que habría debido hacer inexpugnable el núcleo del individualismo, pero que terminaba vaciándolo completamente de sentido.

Volvamos, por el momento, a la que considero la deuda metodológica más profunda de Bobbio con Hobbes. En una primera aproximación, sin duda, la deuda consiste en anteponer la demonstratio a la interpretatio, el principio de razón al principio de autoridad. Hobbes es el príncipe y el pionero del razonamiento geométrico o matematizante aplicado a la política; y Bobbio se encuentra fascinado por esa férrea concatenación de deducciones, aunque no hasta el punto de no ver que bajo la apariencia del puro procedimiento lógico se escondían no sólo discutibles hipótesis metafísicas sino también condicionamientos históricos, además de un cierto número de (pre)juicios antropológicos en sí mismos bastante controvertidos, aunque ciertamente respaldados por evidencias empíricas significativas ${ }^{9}$. Pero la deuda metodológica no consistía sólo en esto. Lo que a mi entender, desde el punto de vista del método, Bobbio apreciaba de Hobbes, y reconocía en él en mayor medida que en ningún otro autor, era el haber puesto de manifiesto que en teoría política - y, especialmente, para fines heurísticos, para la lúcida comprensión de la «razón social» de la filosofía o ciencia política y de sus palabras-clave - el razonamiento dicotómico o dilemático era el más adecuado, cuando no incluso la única forma de razonamiento. La praxis y la historia son el reino de los compromisos, las mediaciones, los matices y la multiplicidad de casos que han de ser tomados en consideración. De ellos hay que hacerse cargo cuando se hace teoría y ésta, si lo que se pretende es proyectar luz sobre la praxis, sobre los acontecimientos históricos -es indiferente aquí si con el objeto de criticarlos o de justificar sus resultadosdebe ser radical, extrema, o, si se quiere, extremista. Debe liberarse de las sofocantes ataduras de lo contingente para de ese modo identificar y señalar los cruces de caminos, las disyuntivas de la política práctica y, en general, de la historia. La radicalidad teórica, el aut aut, es el precio que hay que pagar en aras a la lucidez analítica: lo cual no implica en absoluto, lo subrayo, radicalidad o extremismo político.

En el caso específico, el radicalismo teórico de Hobbes consiste principalmente en rechazar la tradicional visión del mundo holista-organicista y en sustituirla con un alternativa tajante, la visión del mundo individualista-mecanicis-

${ }^{9}$ En otros términos, la aspiración hobbesiana de deducir la filosofía civil de la filosofía primera encierra numerosas dificultades, la más evidente de las cuales consiste precisamente en la posibilidad de deducir una concepción pesimista de la naturaleza humana partiendo del materialismo mecanicista. 
ta, para construir así un marco teórico capaz de dar cabida a la más coherente justificación de la obligación política por medio de los elementos constitutivos del modelo dicotómico - la «gran dicotomía» que preside el universo de la política moderna: estado de naturaleza/sociedad civil—, un modelo que, en opinión de Bobbio, puede ser definido precisamente como hobbesiano. La influencia es más clara e intensa en los lugares en que Bobbio no interpreta a Hobbes, sino que afronta el tema de las dicotomías y de las grandes dicotomías en sí mismas, entendidas como el único método que los seres humanos tienen a su disposición para ordenar la esfera práctica y para orientarse (en el plano descriptivo, prescriptivo, historiográfico) dentro de ella: «toda la historia de las reflexiones (o fabulaciones) del hombre sobre su vida en sociedad está caracterizada por la construcción de «grandes dicotomías», empezando por la que se establece entre estado de inocencia y de corrupción» ${ }^{10}$.

Toda la historia - obsérvese - y no sólo los dos siglos de contractualismo. No en vano, el ensayo de donde proviene esta cita está dedicado al pensamiento dicotómico de Hayek. Bobbio parece hacer alusión al hecho de que el proceder siguiendo dicotomías y dilemas es el único método que consiente el correcto funcionamiento de la razón práctica, o que es incluso coesencial al pensamiento en general ${ }^{11}$. En efecto, según Bobbio, incluso el pensamiento tricotómico encuentra en realidad su fundamento en una variante (en una duplicación dentro de uno de los elementos, un movimiento de retorno) de un esquema esencialmente dicotómico. Sin ignorar «las cumbres del pensamiento tricotómico» - los ejemplos son Vico, Comte y obviamente Hegel—, Bobbio observa que muchas aparentes tricotomías son, sobre todo en el ámbito de la filosofía de la historia, dicotomías menos rudimentales, más sofisticadas: y no se refiere sólo a las variaciones del modelo hobbesiano introducidas por otros contractualistas como Locke y Rousseau, sino también a quienes proponen una interpretación dialéctica de la historia. Un caso típico es el del marxismo que pertenece, «al menos en su aspecto profético, a la historia de las grandes dicotomías (reino de la necesidad / reino de la libertad, prehistoria/ historia, sociedad de clases/sociedad sin clases)» ${ }^{12}$. Si esto es cierto en Marx

10 N. Bobbio, Dalla struttura alla funzione. Nuovi studi di teoria del diritto, Comunità, Milano, 1977, p. 135.

11 Véase cómo define Bobbio las dicotomías y las grandes dicotomías: «En el proceso de ordenación y organización de su campo de investigación toda disciplina tiende a dividir su propio universo de entes en dos subclases que resultan recíprocamente exclusivas y conjuntamente exhaustivas. Para designar el producto de esta operación, que es una operación de clasificación, empleo la expresión «gran dicotomía»: gran en el sentido de total, porque, en la medida en que todos los entes, sin exclusión alguna, a los que actual y potencialmente la disciplina se refiere, han de poder ser incluidos, se diferencia de las dicotomías parciales, en las que se incluye sólo una parte de ellos; y también en el sentido de principal, porque, en la medida en que tiende a hacer converger sobre sí, a resolver, a fundar las demás dicotomías, se diferencia de otras distinciones, que aún siendo exhaustivas pueden considerarse, en comparación con ella, secundarias» (ibidem, p. 145).

12 Ibidem, p. 136. 
y Engels, entonces se podría pensar que todo el pensamiento tricotómico no fuera nada más que el pensamiento dicotómico ordenado por tríadas y no por díadas, esto es, «el uso triádico de una dicotomía [...] asociado con la interpretación dialéctica del curso histórico» ${ }^{13}$. Pese a que Bobbio ve en Hegel el modelo auténtico del pensamiento tricotómico, sus estudios hegelianos constituyen un buen ejemplo de enunciación por medio de dicotomías de aquello que es realmente importante en la filosofía política hegeliana ${ }^{14}$.

El pensar por dicotomías no comienza ciertamente con Hobbes: baste pensar que la gran dicotomía por excelencia es, para Bobbio, la de lo público y lo privado que remite a tiempos muy anteriores a Hobbes y encuentra su fundamento en el derecho romano recogido en el Corpus iuris civilis. En todo caso, Bobbio parece reconocerle a Hobbes el mérito de haber convertido el proceder por dicotomías en el arma más afilada de la argumentación racional en la esfera práctica, y de haberle, por así decir, legado esa arma heurística y expositiva. Un arma que quizá no sirva para resolver tensiones y contradicciones, pero que sin duda permite aclarar muchas de ellas, ilustrando su naturaleza y su razón de ser. De este modo, la lucidez y precisión del razonamiento de Bobbio resultar ser fruto de su talento natural combinado con la fascinación de la lectura del autor del De cive y del Leviatán.

\section{3. ¿Confusing clarity?}

Dicho esto, y antes de pasar al análisis de la otra gran influencia de Hobbes sobre Bobbio, el individualismo, quienes estén familiarizados con la literatura hobbesiana no pueden no recordar un ensayo de Roland Pennock, que llevaba el desafiante título de Hobbes's confusing "clarity». The case of «liberty», que se cierra con un ataque demoledor a Hobbes: «[...] Así pues, parecería que o bien hay locura en su método, o método en su locura, o las dos cosas a la vez» ${ }^{15}$. Lo que Pennock rechaza con énfasis — en general, y no sólo en relación con la noción de libertad- es precisamente la apariencia de claridad y fuerza demostrativa del pensamiento hobbesiano, el cual sin embargo, cuando se aprende a bucear bajo la superficie, se vuelve confuso, un conjunto de definiciones y demostraciones vacías, fruto de un uso perverso de la lógica. Prosigue Pennock: «La filosofía política de Hobbes contiene tal

13 Ibidem, p. 137.

14 Bastará recordar aquí el ensayo Derecho privado y derecho público en Hegel, que se abre con las siguientes palabras: «La «gran dicotomía» del universo jurídico, es decir, la distinción entre derecho privado y derecho público, ocupa a mi juicio un lugar muy relevante en el sistema conceptual de Hegel [...]», incluido en N. Bobbio, Estudios de historia de la filosofía: de Hobbes a Gramsci, Debate, Madrid, 1985, p. 211.

15 J. R. Pennock, Hobbes's confusing clarity en K. C. Brown (ed.), Hobbes Studies, Blackwell, Oxford, 1965, p. 116. 
cantidad de confusiones e inconsistencias que no pueden ser reconducidas a una única explicación. Probablemente lo que más se aproxima a una explicación como ésa se encuentra en los términos de su metodología, en su propensión a los argumentos de «todo o nada», en su rechazo a definir y considerar las cosas desde una perspectiva gradualista ${ }^{16}$. El objetivo polémico último parece ser precisamente ese pensamiento dilemático que tanto admiraba Bobbio en Hobbes.

No analizaré en esta ocasión el ensayo de Pennock, si bien siempre he pensado que está construido sobre algo así como un truco efectista y no sobre una argumentación bien trabada. Pero no podemos evitar preguntarnos si tiene sentido o no dirigir esta misma crítica a Bobbio. Especialmente porque, siquiera en términos menos directos, la acusación de haber comprimido todo el pensamiento político por medio de (y a) las grandes dicotomías y de (a) las demás dicotomías que de las primeras se derivan no era meramente hipotética, sino que circulaba realmente como moneda de cambio entre los historiadores del pensamiento político, a juzgar por la explícita defensa del método histórico-dicotómico que Bobbio se siente en la obligación de llevar a cabo, enfrentándose a las diversas formas de historiografía de raíz lato sensu idealístico-marxiana, precisamente en aquellos pasajes en los que introduce el modelo hobbesiano como la alternativa de los «modernos» frente a un modelo como el aristotélico que había estado vigente a lo largo de los siglos.

En todo caso, ¿hay indicios de que Bobbio hubiera caído en la confusing clarity y de que fuera incapaz de comprender lo que son matters of degree? Creo que absolutamente no. Lo que Bobbio pretendía hacer, también en este caso con asonancias hobbesianas, era distinguir adecuadamente - sin llegar a desconectar completamente, como hace tanta filosofía analítica anglosajona- los modelos teóricos puros (independientemente de que se presenten como descriptivos o prescriptivos, o como filosofías de la historia) y los enrevesados acontecimientos históricos, esto es, el desarrollo inevitablemente ambiguo de los acontecimientos, sus mediaciones, las siempre imperfectas (por lo menos desde el punto de vista de los modelos) realidades institucionales que ese desarrollo produce. Ya el propio Hobbes respondía irritado a quienes le preguntaban que dónde se había llegado a dar un estado de naturaleza como el suyo que no era más que una hipótesis de la razón, ciertamente cargada de manifestaciones históricos en escalas y gradaciones diversas, y que su propósito era construir una perfecta teoría de la obligación política y no reconstruir los procesos históricos que habían llevado a la génesis de los Estados existentes. Las grandes dicotomías, las dicotomías secundarias y todo el arte de la distinción que privilegia el aut aut, el tertium non datur, son claves de acceso a la comprensión de la realidad precisamente porque ésta es en sí misma ambigua y proteiforme, porque ofrece solamente mezclas e híbridos

16 Ibidem, pp. 115-16. 
más o menos monstruosos. Sabemos bien, por ejemplo, que en la historia no se dan democracias o autocracias puras, sino sólo combinaciones que se sitúan en algún punto de una línea en cuyos extremos se sitúan la democracia y la autocracia puras. Es, justamente, una cuestión de grados, de mayor o menor distancia respecto de uno de los dos extremos. Pero para entender en qué consiste la democracia y en qué consiste la autocracia, y, por tanto, para intentar identificar cuál es el punto intermedio en que se sitúa un determinado Estado históricamente existente necesitamos razonar previamente en términos dilemáticos: en este caso, poder ascendente frente a poder descendente.

Lo realmente importante es no confundir la teoría con la ideología, como a menudo hacían precisamente quienes le reprochaban a Bobbio el reduccionismo de una modelística fácil y engañosa. La ideología pretende, ahora sí de forma engañosa y trágica, que la realidad se pliegue de forma maniquea a una explicación y a una solución sencilla y absoluta. Éste es, en todo caso, el punto que Bobbio aclara perfectamente en la sede en la que menos hubiéramos esperado, en un artículo de periódico:

Toda la historia humana es un continuo movimiento de impulsos y contraimpulsos, y parece hecha a propósito para darle la razón a los que no quieren interpretarla según la lógica de la contradicción o del tercero excluido, tan apreciada por los ideólogos del «socialismo o barbarie» o, viceversa, del «capitalismo o Gulag». El principio de la historia es, por el contrario, el principio del «tercero excluido», que puede interpretarse según los gustos, tanto con fórmulas aproximativas e insatisfactorias como con síntesis de los opuestos, en la que el «tercero» incluye los primeros dos momentos, o como mediación entre los dos extremos, en los que los otros dos momentos son del «tercero» excluido o, más directamente, como compromiso donde el «tercero» es algo que tiene un poco del uno y del otro (sí, la historia avanza a través de compromisos aunque no todos los compromisos son históricos) ${ }^{17}$.

El ejemplo ofrecido por Bobbio era, y no por simple casualidad, precisamente el de la lucha secular entre la supremacía del rey y el parlamento, donde - en buena lógica hobbesiana - el poder soberano, para ser realmente soberano, no hubiera podido ser poder dividido. En cambio, observa Bobbio, «surgió esa síntesis, o menos noblemente eso que no es ni carne ni pescado, o más vulgarmente ese compromiso, que fue la monarquía constitucional, que duró a través del tiempo y cumplió su función histórica ya por nadie cuestionada» ${ }^{18}$. Pero no es posible entender cabalmente qué tipo de compromiso se daba en la monarquía constitucional mientras no se tome en serio el argumento hobbesiano de la indivisibilidad del poder soberano, que el propio Bobbio considera fundado sobre «uno de sus típicos argumentos dilemáticos» ${ }^{19}$. De

17 ¿Una sociedad nunca vista?, «Avanti!», 11 de marzo de 1978, ahora incluido en N. Bobbio, Las ideologías y el poder en crisis, Ariel, Barcelona, 1988, pp. 63-4.

18 Ibidem.

19 N. Bobbio, Thomas Hobbes, Plaza y Janés, Barcelona, 1991, p. 78. 
este modo, la sospecha de la confusing clarity afecta no tanto a Hobbes y a Bobbio cuanto a los historiadores y filósofos que no son capaces ni de iluminar la historia con la teoría, ni la teoría con la historia, prestando atención, cuando corresponde, a sus duras lecciones.

\section{Individualismo y Estado moderno}

Prima facie, la segunda gran deuda que Bobbio le reconoce a Hobbes podría ser considerada como la anterior superficial y en definitiva genérica. Como es sabido, Hobbes propuso una fundamentación individualista y una visión artificialista de la política en clara oposición al holismo y al organicismo antiguo. El átomo de la sociedad y de la política es el individuo y no la célula representada por la familia, la unión mínima del hombre y la mujer, como sostenía Aristóteles. Eso mismo es lo que pensaba Bobbio. Podría objetarse, sin embargo, echando una simple ojeada más allá de esta por lo demás amplísima visión metafísica, que la concepción individualista que Bobbio pone en la base de la democracia moderna se asocia a la primacía de los derechos sobre los deberes y sobre todo a las cuatro grandes libertades de los modernos (personal, de expresión, de reunión y de asociación), premisas indispensables para que los derechos políticos y el sufragio universal puedan ser considerados como el método para expresar responsablemente, aunque de manera indirecta, preferencias sobre programas políticos alternativos y no simplemente como instrumento para la elección de un caudillo o líder al que confiar las decisiones colectivas. Significa, por consiguiente, situar (en último término) en el individuo y en sus derechos los límites del poder político: todo lo contrario que esa «gramática de la obediencia» casi sin límites que escribió Hobbes. Hay, pues, una buena distancia entre la libertad residual de los ciudadanos-súbditos hobbesianos y los derechos subjetivos de libertad garantizados por el Estado democrático de derecho — del que Bobbio ha sido siempre un tenaz defensor-. Y los límites fácticos que Hobbes recomienda respetar al soberano sobre la única base de la prudencia política, es decir, de una especie de «deontología profesional» o de «vínculo de racionalidad», que son cosas bien distintas a la sumisión a la ley dictada por el soberano que demanda el constitucionalismo moderno ${ }^{20}$. No obstante, en el fondo, lo que el constitucionalismo demanda es precisamente la transformación, por medio de un nuevo acto de racionalidad, de dicho vínculo en derecho positivo.

20 Tanto en el De cive (cap. XIII) como en el Leviatán (cap. XXX) Hobbes afirma claramente, y con insistencia, que un soberano que, aún teniendo facultad para ello, gobierne de forma arbitraria e irracional acabará debilitando al Estado, y por tanto debilitándose a sí mismo y exponiéndose al riesgo de la rebelión. Pero también, con la misma claridad, que esa exigencia de racionalidad no podrá nunca ser incorporada por medio de vínculos constitucionales al dispositivo lógico que desemboca en el pacto de unión. 
Es cierto que Bobbio, en su desarrollo del eje central del «modelo hobbesiano», declara rotundamente que el individualismo está en la base de la democracia moderna en la medida en que es el presupuesto para pensar la naturaleza artificial y contractual del Estado, y, por tanto, para reconocer su origen consensual que se manifiesta por entero y se afirma precisamente en la forma más evolucionada del Estado territorial moderno, el Estado democrático de derecho. Aunque indiscutibles, no son estos, a mi entender, los únicos aspectos que han de ser tenidos en cuenta si lo que se pretende es indagar en profundidad la influencia del individualismo hobbesiano sobre la filosofía política de Bobbio. Repito: del individualismo en la forma específica que le dio Hobbes, y no de la más amplia corriente teórica que constituye el iusnaturalismo moderno, en la que se sitúan tanto Hobbes como Rousseau, tanto Locke como Kant. A mi me parece que dicha influencia se manifiesta en dos direcciones diferentes pero conectadas entre sí: esto es, en el rechazo del «individualismo propietario» de Locke y de gran parte de la tradición liberal y en la insatisfacción, próxima ya a la intolerancia, respecto del llamado «individualismo metodológico» que llegó a ser dominante en las ciencias económicas y sociales de los siglos XIX y XX.

Por lo que se refiere al rechazo del individualismo propietario será suficiente reflejar la crítica que le dirige Bobbio, poniéndolo en oposición al individualismo democrático:

Hay individualismos e individualismos. Existe el individualismo de la tradición liberal-libertaria y el de la tradición democrática. El primero arranca al individuo del cuerpo orgánico de la sociedad y lo hace vivir fuera del seno materno metiéndolo en el mundo desconocido y lleno de peligros de la lucha por la supervivencia, donde cada cual debe velar por sí mismo, en una lucha perpetua, ejemplificada por el hobbesiano bellum omnium contra omnes. El segundo lo reintegra a sus semejantes para que de su unión la sociedad sea considerada ya no como un todo orgánico del que brotó, sino como una asociación de individuos libres. El primero reivindica la libertad del individuo frente a la sociedad; el segundo lo reconcilia con la sociedad haciendo de ésta el resultado de un acuerdo libre entre individuos inteligentes. El primero hace del individuo un protagonista absoluto, fuera de cualquier vínculo social; el segundo lo hace protagonista de una nueva sociedad que emerge de las cenizas de la antigua, en la que las decisiones colectivas son tomadas por los mismos individuos o por sus representantes ${ }^{21}$.

En este fragmento está contenido, a mi juicio, el sentido más profundo del universo moral y político que Bobbio perseguía, y que alimentaba su pasión cívica. Es, en el fondo, una reflexión que asume no sólo los términos y modalidades hobbesianas —el razonamiento es claramente dilemático — sino también, implícita o explícitamente, los elementos fundamentales del pensamiento de Hobbes.

21 Bobbio, Teoría general, cit., pp. 412-413. 
Señalaré dos de ellos, estrechamente conectados entre sí: a) el individualismo liberal-libertario y/o propietario, responsable de ese «Estado mínimo» que desde una perspectiva como la de Hobbes adolece de casi todas las características propias de la soberanía y que, en la de Bobbio, no sirve para emancipar al individuo de la lucha por la supervivencia característica del Estado de naturaleza, pues constituye tan solo una variante menos sangrienta y miserable de ese bellum omnium contra omnes cuya superación era la finalidad del artificio político hobbesiano; b) el rechazo de la idea de que la propiedad y la facultad de su acumulación ilimitada están en la naturaleza de las cosas y se identifican con el sentido de la existencia individual, de tal manera que su protección representa la principal, cuando no exclusiva, razón de ser del Estado.

Hobbes rechaza con fuerza - ante litteram - cualquier posible solución libertaria [y libelista] al reivindicar para el soberano y, por tanto, para una dimensión pública, colectiva, política, el poder de asignar, sustraer y redistribuir a los individuos convertidos en ciudadanos los títulos de propiedad y la posesión material de los bienes. Bobbio la rechaza sin rechazar el liberalismo de los derechos, es decir, a partir de la fórmula de la «reconciliación» del individuo con la sociedad, propia del individualismo democrático que, en otros términos, equivale a la primacía de la política sobre la economía; de la misma forma que la «reunificación» del individuo con la sociedad, también atribuida por Bobbio al individualismo democrático, expresa la primacía del derecho sobre la economía. En la versión bobbiana esta primacía se identifica con la idea de que los derechos fundamentales de los individuos - cuya «unión», palabra clave ya en Hobbes, forma la sociedad - constituye la red de aquello que más adelante Habermas denominaría la «solidaridad entre extraños». Por medio de la atribución y la garantía de un conjunto de derechos fundamentales, netamente diferenciados de los derechos de propiedad particulares, los ordenamientos jurídicos de las democracias se proponen (¿o debieran proponerse?) limitar los efectos perversos del mercado y de sus poderes salvajes - efectos y poderes derivados, indirectamente, precisamente de esa ideología del «protagonismo absoluto» (de la libertad absoluta) de individuos que en la práctica actúan como si no tuvieran ninguna clase de vínculo social一. En otros términos, el constitucionalismo de los derechos, entendido como «ley del más débil», no puede hacer más que rechazar el libertarismo en cuanto forma de superhomismo económico, que olvida la lección hobbesiana de la igualdad natural entre individuos que, en último extremo, son frágiles. Si reproducimos, sugiere Bobbio, por medio del «mercado» condiciones comparables a las del estado de naturaleza, nadie, por muy capaz e inteligente que se considere, podrá estar seguro de no verse marginado o derrotado.

La apuesta absoluta por la libre competencia y negociación entre individuos, cortados los lazos con los orígenes éticos de la noción de individuo, se expresa en formas rígidas, cuando no dogmáticas, de individualismo metodo- 
lógico, formas que ya no guardan más que una apariencia de neutralidad ideológica. Esta declinación del individualismo era el blanco de las observaciones críticas de un individualista como Bobbio:

En su origen, el individualismo es una ontología y una ética: una ontología en cuanto se inserta en una concepción atomista de la sociedad (y de la naturaleza), opuesta a la concepción orgánica dominante; una ética, en cuanto que el ser humano, a diferencia de todos los demás entes del mundo natural, tiene un valor moral o, para decirlo en términos de Kant, una dignidad y no sólo un precio. Es decir, que al llegar a nuestros tiempos, el individualismo se ha vuelto un método (me refiero al llamado «individualismo metodológico» defendido por sociólogos y economistas en estos años), o sea la expresión de una preferencia, con todas las consecuencias que de ahí se derivan, en el estudio de los fenómenos sociales, al tomar como punto de partida las acciones individuales más que las de las varias formas de sociedad en su conjunto 22 .

Y en otro lugar precisaba:

[...] La idea individualista se ha puesto las vestimentas más humildes del individualismo metodológico [...]. En este sentido son individualistas dos de los más complejos sistemas sociológicos de nuestro siglo, el de Pareto y el de Weber. [...] De cualquier modo, convendría no olvidar, para prevenir toda indebida absolutización de un método, que el individualismo metodológico nació en el seno de los estudios económicos, que es aquí donde tiene su fuerza operativa (no por casualidad Pareto y Weber eran dos sociólogos economistas) y que no puede ser trasplantado a otros campos donde los fenómenos colectivos, como el lenguaje y en parte también el derecho, no pueden ser explicados a partir del individuo y de sus preferencias, y en cuanto tales siempre han alimentado y legitimado, bajo una absolutización en sentido contrario e igualmente incorrecta, teorías organicistas ${ }^{23}$.

Releyendo estos fragmentos puede parecer que la afirmación de que ha existido una influencia de Hobbes sobre el individualismo democrático de Bobbio es demasiado forzada. No hay duda de que Bobbio tiene bien presente a Hobbes, por ejemplo cuando identifica el origen ontológico del individualismo en el atomismo de la filosofía natural y en el nominalismo lógico. Pero él sabe bien que esa filosofía natural y ese nominalismo se han vuelto herramientas viejas, que están fuera de juego tanto desde el punto de vista filosófico como científico. La distinción que sigue siendo actual es más bien la que se da entre individualismo ético y metodológico. Y ahí es donde Hobbes vuelve a asomar en el razonamiento de Bobbio, aunque - diríamos- por oposición a Kant, para quien el individuo posee, ante todo, su dignidad y no ese precio que para Hobbes era medida de lo que podríamos llamar su valor

22 Ibidem, p. 423.

23 Ibidem, pp. 412. 
de mercado. En definitiva, parece que Bobbio se aparta prima facie de Hobbes y se pone del lado del individualismo ético de Kant.

Por lo demás, Hobbes suele ser considerado como el precursor de la teoría de juegos y, en general, de la racional choice, y por consiguiente también de las versiones más recientes y autorizadas del llamado «individualismo metodológico». Teorías de cuyas aplicaciones indiscriminadas y «universalistas», de las que deriva una visión estrechamente economicista del mundo y las relaciones entre individuos, Bobbio nos invita claramente a desconfiar. Una vez más, porque un método y una teoría que pretendan explicarlo todo con las categorías de una única disciplina esconden un fondo ideológico, cuando no la intención de hacer ideología. El recurso a la figura anodina del elector racional encubre el riesgo del reduccionismo utilitarista, de hacer una teoría de la preferencia que reconduce cualquier elección a los criterios de la economía de mercado. Pero sólo desde una argumentación simplista una posición como ésta puede ser reconducida a la afirmación hobbesiana de que «la medida del derecho es la utilidad» ${ }^{24}$. Por el contrario, del contexto en que aparece dicha afirmación se desprende que Hobbes no es un precedente del utilitarismo de las preferencias y, en general, de una visión del mundo centrada sobre la entonces emergente economía de mercado. Porque Hobbes precisa: «en el estado de naturaleza», es decir, precisamente en el estado que los individuos deben hacer lo posible por abandonar mediante ese cálculo de utilidad a largo plazo que constituye el presupuesto del «pacto de unión» y del ingreso en la «sociedad civil».

Regresamos, de este modo, a la concepción bobbiana del individualismo en la cual no se cortan los puentes entre el individuo y la sociedad, sino que se articulan y refuerzan a través de la responsabilidad política y la mediación del derecho. Y por esta vía encontramos también, en mi opinión, un nuevo y específico legado de Hobbes en Bobbio. Intentaré explicarme mejor. Dije antes que Bobbio parece preferir, por sí mismo y también como fundamento de la democracia moderna, el individualismo ético de matriz kantiana. Pero Bobbio es consciente de que con el innatismo kantiano se corre el peligro de recuperar un elemento determinante de la doctrina clásica del derecho natural, poniendo en tela de juicio nuevamente la artificialidad del derecho, el iuspositivismo, y, de su mano, toda la construcción del Estado moderno como autoridad que establece las normas de la convivencia civil. El individualismo ético, el valor inconmensurable de la vida y de la autonomía de todos los seres humanos presupone, en efecto, la existencia y la cognoscibilidad de un orden «verdadero» del mundo - y por tanto de un Naturrecht al que deberá adecuarse el derecho positivo.

En Hobbes, en cambio, el único orden comprensible para los seres humanos es el que ellos mismos han creado artificialmente. El propio materialismo

${ }^{24}$ De cive, I, 10. 
mecanicista es considerado tan sólo como una hipótesis acerca del orden del mundo, aunque la más plausible. La política y el derecho son órdenes completamente artificiales. No obstante ello no significa que lo que sobrevive del individualismo hobbesiano sea únicamente el aspecto metodológico, esto es, la idea de desmontar el Estado en sus unidades fundamentales para explicar su funcionamiento, según la célebre metáfora del reloj. Cuando de lo que se trata es de volver a montar ese mismo reloj nos damos cuenta de que hay algo más. Nos topamos con la gran importancia otorgada por Hobbes a esas indicaciones o prescripciones prudenciales que el filósofo inglés todavía denominaba, en homenaje a la tradición, leyes naturales: y la importancia radica en el hecho de que ése es el lugar para la definición de las condiciones con arreglo a las cuales el acuerdo, el pacto constitutivo del Estado, resultará aceptable para los individuos. Para los futuros contrayentes el núcleo irrenunciable de estas condiciones, de esta especie de compromiso previo, consiste en reconocerse recíprocamente como iguales. Si se quiere evitar que fracase, el pacto tiene que haber sido establecido entre individuos moral, política e incluso económicamente similares: nadie puede reivindicar, por medio de cláusulas particulares, la obtención de algo más el día después sosteniendo que ha tenido que renunciar a algo más el día antes. En otros términos, con Hobbes se llega al reconocimiento de la igualdad moral entre los individuos mediante el recurso a un argumento utilitario: el individualismo ético, si se quiere, no depende ya del reconocimiento de una evidencia natural, sino que se convierte en instrumento, en un camino útil para llegar a construir las condiciones de la convivencia pacífica.

El individualismo democrático defendido por Bobbio parte de estos presupuestos éticos, reconducibles tanto a Hobbes como Kant, pero también, en último término, más a Hobbes que a Kant. No en vano Bobbio hace hincapié en el hecho de que el individualismo democrático reúne al individuo con sus semejantes, los cuales han de ser reconocidos como semejantes, sugiriendo así que el punto de partida que el punto de partida hobbesiano es el que resulta verdaderamente irrenunciable. Naturalmente en Bobbio, y sin duda la diferencia no es pequeña, las cuestiones de justicia y, en particular, las condiciones para modular las desigualdades entre individuos siguen jugando un papel destacado también después de que el Estado ha llegado a constituirse. Se trata del proceso de desarrollo de los derechos fundamentales que nos ha llevado del Estado absoluto al Estado democrático de derecho; un proceso que sigue abierto tanto por lo que respecta a los conflictos políticos y sociales como a la «crítica externa» que la filosofía política normativa debe poder dirigir al derecho y a quien lo produce, esto es, al legislador y a los propios Tribunales Constitucionales. 


\section{Sobre la «fortuna» de Hobbes y de Bobbio}

Antes de concluir con una prudente comparación de la fortuna, aparentemente contraria, de los dos autores, añadiré una breve consideración más, poco más que superficial, sobre el pesimismo acerca de la naturaleza humana y la historia que Bobbio dice haber recibido, casi por contagio, de Hobbes. Curioso pesimismo el de Hobbes y Bobbio. El primero, como no deja de observar precisamente el segundo, elabora su lectura de la condición natural partiendo del homo homini lupus y del carácter inextinguible de la pasión de la vanagloria, pero a continuación considera esos mismos individuos como actores racionales capaces de salir del estado de naturaleza construyendo por la vía del acuerdo nada menos que la gran maquinaria del Estado; el segundo, Bobbio, después de haber puesto lúcidamente de manifiesto la contradicción hobbesiana, sugiere incluso la posibilidad de reproducir el modelo en el ámbito supranacional, introduciendo realmente la figura de un «tercero» que hasta el momento, a pesar de la ONU, ha seguido estando ausente ${ }^{25}$. Esta curiosa forma de pesimismo - o mejor, de inestable pero fecunda tensión entre los aspectos descriptivos y normativos - los sitúa a ambos en la categoría de la ilustración perenne, donde el análisis descarnado de la realidad es considerado como la vía maestra no para la conservación de lo existente sino para identificar e indicar la dirección del progreso civil. Un progreso que, sin duda, no será nunca definitivo y libre de peligros, pero en el que la búsqueda, tan desencantada como ininterrumpida, acaba convirtiéndose en seña de identidad de su pensamiento.

También a propósito de la fortuna - o mejor, de la mala fortuna- de Hobbes podemos tomar como punto de partida un par de valoraciones de Bobbio:

Hobbes está demasiado comprometido en la creación de una teoría coherente para preocuparse por los intereses prácticos de unos y otros; pero a la vez es un investigador demasiado clarividente de la naturaleza humana como para dejarse conmover por los galanteadores de estados ideales. Por una parte, los reaccionarios, como Filmer, y los conservadores, como Clarendon, protestan contra la fundación contractualista del Estado, porque el poder no deriva del consenso popular, sino que es de origen directa o indirectamente divino. Por otra, tampoco el puritano y liberal Lawson acepta el contrato social, sino que lo tacha de elucubración utópica, porque según él el Estado no aparece de repente, sino gradualmente, a través de sucesivos perfeccionamientos de la sociedad humana ${ }^{26}$.

El destino singular de Hobbes fue ser un solitario de su tiempo, no tener discípulos, aunque [...] ejerció una influencia subterránea incluso sobre sus adversarios, que se apropiaron de su forma de razonar y de su método de dis-

${ }^{25}$ Cfr. N. Bobbio, Il terzo assente, Sonda, Torino, 1989.

26 Bobbio, Thomas Hobbes, cit., pp. 293-294 
cutir, en el que se dejaban de lado las controversias sobre los textos sagrados, y para aceptar el desafío tuvieron que descender al terreno de las disputas basadas en la refutación de los hechos y en la negación de los razonamientos. La amplitud, la continuidad y la agria insistencia de las críticas son la mejor prueba de que el desafío fue atendido ${ }^{27}$.

En otras palabras, el anatema, la conventio ad excludendum que cayó sobre Hobbes en los siglos XVI y XVII — que acabaría convirtiéndose a partir del siglo XIX, pero sobre todo a partir de la segunda mitad del XX, también gracias a Bobbio, en un interés quizá sin igual entre los demás filósofos políticosllevaba dentro de sí las razones de su interés: el desafío al principio de autoridad, en el fondo, ya estaba ganado, aunque al método de la argumentación racional le quedaba aún mucho camino para llegar a imponerse.

De entrada, en relación con su «fortuna», el caso de Bobbio parecería igual y contrario. Si en su tiempo Hobbes no tuvo, al menos públicamente, nada más que enemigos, Bobbio no haber tenido más que amigos, o, como mucho, críticos que le mostraban su aprecio. Los reconocimientos han sido numerosísimos y de gran prestigio. Su caso, al menos en Italia, parece ser el de una conventio ad includendum, por la inusitada propensión, en autores de las orientaciones más dispares, a entrar en diálogo con Bobbio, buscando con frecuencia una referencia o el apoyo de una frase brillante. Me pregunto, sin embargo, hasta qué punto ha sido sincera y profunda esta búsqueda de apoyo. Me pregunto, en otras palabras, si y cuánto Bobbio ha sido leído y no sólo citado, comprendido en la compleja articulación de su pensamiento. Y me pregunto, por tanto, si la conventio ad excludendum y la conventio ad includendum no tendrán al final rasgos comunes, no presentan alguna coincidencia; si no existen parecidos o analogías entre la inicial «mala» fortuna de Hobbes y la aparente «gran» fortuna de Bobbio.

No pretendo, por supuesto, apelar a ninguna clase de ortodoxia bobbiana, pues ésta sería justamente una de esas manifestaciones de fanatismo que él detestaba con toda su alma. Son posibles, sin duda, múltiples lecturas de su pensamiento, pero esto no significa en absoluto que todas ellas sean, y deban ser consideradas, igualmente plausibles. En mi opinión, existen diversos ejemplos de impropia y contundente simplificación de las ideas fundamentales de Bobbio. Ciñéndome al caso italiano me gustaría señalar — rapsódicamente, a mero título de ejemplo - cuatro casos, de diferente signo, que tienen que ver con el objeto científico que Bobbio mismo consideraba como el hilo conductor de sus estudios, la teoría de la democracia. Danilo Zolo, en Il principato democratico, convierte a Bobbio en un mero exponente, por cuanto crítico, del paradigma neoclásico de la democracia pluralista, esto es, de la teoría schumpeteriana de la democracia ${ }^{28}$; Anna Pintore, de forma análoga,

27 Ibidem, p. 297-298.

28 Cfr. D. Zolo, Il principato democratico. Per una teoria realistica della democrazia, Feltrinelli, Milano, 1992, passim. 
reduce la teoría bobbiana a un procedimentalismo realista, por contraposición al procedimentalismo hipotético de Rawls y Habermas, convirtiéndola así en una teoría de las puras «reglas del juego» separadas de toda indicación normativa sobre las condiciones en las que el juego y sus reglas adquieren sentido, convirtiéndose en expresión de autonomía moral y política del individuo ${ }^{29}$.

Otros autores, en cambio, consideran a Bobbio — con algunos matices, a mi entender insuficientes - como un defensor de una teoría sustancialista de la democracia. En opinión de Domenico Losurdo, el Bobbio de los años cincuenta y sesenta entendía insuficiente lubricar la máquina del Estado socialista, esto es, de una democracia que se traduce en igualdad económica, con los derechos de libertad de la tradición liberal; las sucesivas y cambiantes opiniones son interpretadas, en algún sentido, como expresiones de un último Bobbio que habría virado irresistiblemente hacia Hayek, hacia una «democracia de mínimos», esto es, hacia una forma de gobierno que no es capaz de ponerle freno a la deriva neoliberal ${ }^{30}$. Recientemente, Luciano Canfora ha recuperado los elementos principales de la interpretación que convierte a Bobbio en un defensor de la democracia sustancial sacando fuera de contexto una frase en la que se lee que «el igualitarismo es la esencia de la democracia» ${ }^{31}$.

La respuesta a estos malentendidos de signo contrario se encuentra, en último término, precisamente en el individualismo, no sólo metodológico, y en la teoría consensual de la obligación política que Bobbio reconoce haber tomado críticamente de Hobbes. Una posición que rechaza claramente tanto el utilitarismo de la preferencia implícito en las teorías económicas de la democracia, como el igualitarismo - la igualdad de todos en todo- y el ensueño de la democracia como «forma de vida» propio de las teorías sustanciales de la misma. Cabe la sospecha de que, en tiempos como los nuestros de secularización sin laicidad, un cierto grado de malentendido, una cita aparentemente

${ }^{29}$ Cfr. A. Pintore, I diritti della democrazia, Laterza, Roma-Bari, 2003, en especial p. 22; pero también Habermas, en Facticidad y validez, considera la teoría democrática de Bobbio como una variante de la de Schumpeter.

30 D. Losurdo, Democrazia o bonapartismo. Trionfo e decadenza del suffragio universale, Bollati Boringhieri, Torino, 1993, pp. 260-63.

31 L. Canfora, La democrazia. Storia di un'ideologia, Laterza, Roma-Bari, 2004, p. 264. En nota (p. 383), Canfora estima oportuno añadir que en escritos posteriores «Bobbio tiende a identificar la democracia con la regla de las mayorías», comiendo de esta forma dos errores de interpretación al mismo tiempo. La frase sobre democracia e igualitarismo se encuentra en la ponencia sobre La ideología del fascismo presentada en Milán el 10 de enero de 1975 con ocasión de la conmemoración del 30 aniversario de la Resistenza. La prueba de que se trata de una frase aislada, que ha de ser interpretada en el desarrollo de ese texto centrado en la contraposición entre fascismo y democracia fundamentalmente en el plano de los valores, nos la ofrece el propio Canfora quien - en un artículo dedicado específicamente a la concepción bobbiana de la democracia: Oscillazioni di un filosofo, "Corriere della Sera», 6/2/2005- no es capaz de aportar ni siquiera un solo texto más de carácter «sustancialista» para ilustrar sus presuntas oscilaciones. 
obligada pero empleada de forma distorsionada, no sea una especie de fariseo sucedáneo de la explícita conventio ad excludendum que cayó sobre Hobbes. Quienes tengan una concepción menos pesimista que la mía de la naturaleza humana y de la historia quizá pensarán que también en el caso de Bobbio, como en el de Hobbes, lo que hace falta es simplemente algo más de tiempo, el que se necesita para llevar a cabo el trabajo de análisis pormenorizado y reflexión sistemática, para identificar en sus páginas el significado general de un extraordinario itinerario intelectual.

Por el momento, nos vemos obligados a suspender el juicio. Quisiera, sin embargo, terminar con un pasaje de Bobbio en el que se resumen las razones por las que el pensamiento de Hobbes ha logrado superar la prueba del tiempo:

El problema que se le plantea al historiador de las doctrinas políticas ante estos críticos de Hobbes es el siguiente: las críticas, tomadas una por una, parecen válidas y eficaces, y sin embargo el monumento hobbesiano se ha mantenido perfectamente en pie hasta hoy. Los críticos de Hobbes dicen, quien más quien menos, cosas justas y sacrosantas, pero Hobbes es un gran escritor político que, él sí, ha dejado una profunda huella, mientras que sus críticos, con la excepción quizá de Bramhall y Lawson, son escritores de segunda fila a los que, para exhumarlos, hay que quitarles el polvo que se ha acumulado en sus páginas en las viejas bibliotecas ${ }^{32}$.

Es posible que un día la reconstrucción de la «fortuna» de Bobbio pueda ser descrita con palabras semejantes a éstas.

32 Bobbio, Thomas Hobbes, cit., p. 294. 